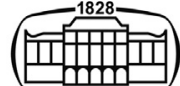

AKADÉMIAI KIADÓ

Pollack Periodica

An International Journal

for Engineering and

Information Sciences

16 (2021) 2, 117-123

DOI:

10.1556/606.2020.00207

(c) 2020 The Author(s)

\section{ORIGINAL RESEARCH}

\section{PAPER}

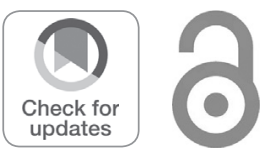

\title{
Building thermal capacity for peak shifting, based on PV surplus production
}

\author{
Istvan Ervin Haber ${ }^{1,2 *}$ (D), Gergely Bencsik ${ }^{3}$, Basma Naili ${ }^{4}$ and \\ Istvan Szabo ${ }^{5}$
}

\footnotetext{
${ }^{1}$ Department of Mechanical Engineering, Institute of Smart Technology and Engineering, Faculty of Engineering and Information Technology, Boszorkány út 2, H-7624 Pécs, Hungary

${ }^{2}$ Energy Design Building Technology Research Group, Szentágothai Research Centre, University of Pécs, Ifjúság útja 20, H-7624 Pécs, Hungary

${ }^{3}$ Renergy Consulting Ltd, Tettye d. 2/1, H-7625 Pécs, Hungary

${ }^{4}$ Marcel Breuer Doctoral School, Institute of Architecture, Faculty of Engineering and Information Technology, University of Pécs, Boszorkány út 2, H-7624 Pécs, Hungary

${ }^{5}$ Department of Control Systems, Institute of Information Technology, University of Dunaujvaros, Dunaujvaros, H-2401, Hungary
}

Received: February 13, 2020 • Revised manuscript received: May 29, 2020 - Accepted: June 25, 2020 Published online: March 23, 2021

\section{ABSTRACT}

Energy storage on grid level is still a critical issue. Inventions related to development and control of smart buildings, including integrated solar systems can be easily realized by smart control of building management including storage. At buildings, which have high heat capacitance the part of the stored heat can be used for grid stabilization. This means the grid can be balanced with well-set up heating/ cooling strategy and well-scheduled timetable via intelligent control of buildings. A possible solution is introduced in this paper, where the surplus production is used for overcooling the building, while the building thermodynamic properties are making it possible to store this amount of energy for days. This paper analyses a cost-effective solution of grid energy storage through a case study.

\section{KEYWORDS}

grid energy storage, intelligent building management, thermal storage, photovoltaics, smart grid, smart city

\section{INTRODUCTION}

Renewable energy production trend runs on uncertain way, which is shown on the German example where in 11th May of 2016 renewable energy production reached the level, when electric energy market could not accommodate the available renewable energy and the market price turned to negative. This will happen more frequently in the future, so time has come to go smarter. Grid operator, Transmission System Operators (TSOs), Distribution System Operators (DSOs), or grid end-users should provide solutions for storage capacity or any alternative technology solution, which is able to manage the excess energy. The system, which is able to handle the issue is called smart grid. This system is the 21 st century vision of electrical grid, including a wide variety of technologies: sensors, smart meters, smart appliances, renewable energy resources, energy efficiency resources and storage systems, intelligent overall central control of smart devices.

Continuous control of the production, distribution, load regulation and storage of electricity are important aspects of smart grid. The US Energy Independence and Security Act of 2007 [1] declares, that peak shaving technologies with electricity storage systems (including electric vehicle storage) and thermal air conditioning are mandatory fields of the smart grid discussion. 
A base list of technologies of Energy Storage Systems (ESSs): It can be a battery system (electro-chemical storage also built-in battery packs of electric vehicles), or compressed/liquid air storage, or hydro pump systems as well as hydrogen storage, or electro mechanical (flywheel) storage system and at last but not at least thermal storage systems. The rated power of hydro pumped systems were $185 \mathrm{GW}, 4$ GW of thermal storage, $4.4 \mathrm{GW}$ battery, 2.6 GW electromechanical, and the other solutions, all together the installed storage power worldwide is far less than $1 \mathrm{TW}$, in 2017, [2]. The cost starts from $350 \$ / \mathrm{kWh}$ for sodium/sulfur batteries and goes until 1,200 $\$ / \mathrm{kWh}$ at pumped hydro systems as an average, [3].

Pumped hydro systems are the etalon solution of energy storage. Benchmarking the thermal storage (a Seasonal Thermal Heat Storage (STES), the Latent Thermal Heat Storage (LTES), or Chemical Thermal Heat Storage (CTES) $[4,5])$ can have higher energy density and the storage costs are similar. As emerging solution some buildings can be used also as heat storage when these have increased thermal capacitance [6].

New solutions (demand side management, net metering as framework of Internet of Things (IoTs)) as parts of the smart grid help to distribute energy and to optimize the use of energy. The smart net metering effects on the consumption when Renewable Energy Credits (RECs) is used.

\subsection{Smart micro-grids with energy storage systems}

Smart micro-grids have been identified as essential components of future power systems with the potential to assist with energy security, environmental sustainability and energy equity challenges the population is facing globally [7].

Smart grid (Fig. 1) today means the local grid is connected to electrical network, but this can work autonomously as a balanced local grid. From this sight the following systems can name [8]:
1. Autonomous: Total energy need is provided by built-in capacity of the grid;

2. Partially autonomous: Taken into consideration the economic aspects the predictable demands will be covered, only. Typically it works with renewable energy production. It does not produce high amount excess energy. It identifies the future load demands and storage capacities according to the real consumer needs;

3. Grid connected micro-grid, designed for large scale consumption need.

Energy storage ensures the smart grid's autonomy. The key criteria of a smart city are that the produced goods (also the energy) have to be used up locally and following the principle this is how the smallest ecological footprint will be achieved.

Numerous control methods for energy management systems have been developed for smart grids to distribute energy between consumers, ESS and production sites. Newton-Raphson technique-based method exist [9], recursive least square methods [7], space vector pulse-width modulation [10], and also genetic algorithm-based control systems [11], but all agrees, that weather forecast must be applied for lower uncertainty in the system.

The micro-grid can be Alternating Current (AC) or Direct Current (DC) base network, but it becomes even more perspective, as the small size DC micro-grid has lower losses, based on the demonstration experiment at Okinawa Campus project verified the effectiveness of DC based Open Energy System (DCOES) [12].

Let's take into consideration an ideal model for distributed energy storage system in micro-grid. When electrical storage is full, then peak excess energy generation is fed as heat into buildings. This cannot be regenerated and "repumped" to electrical grid but when the capacity and the heat resistance of the building envelope is high enough the stored energy can be used for long period of time, making

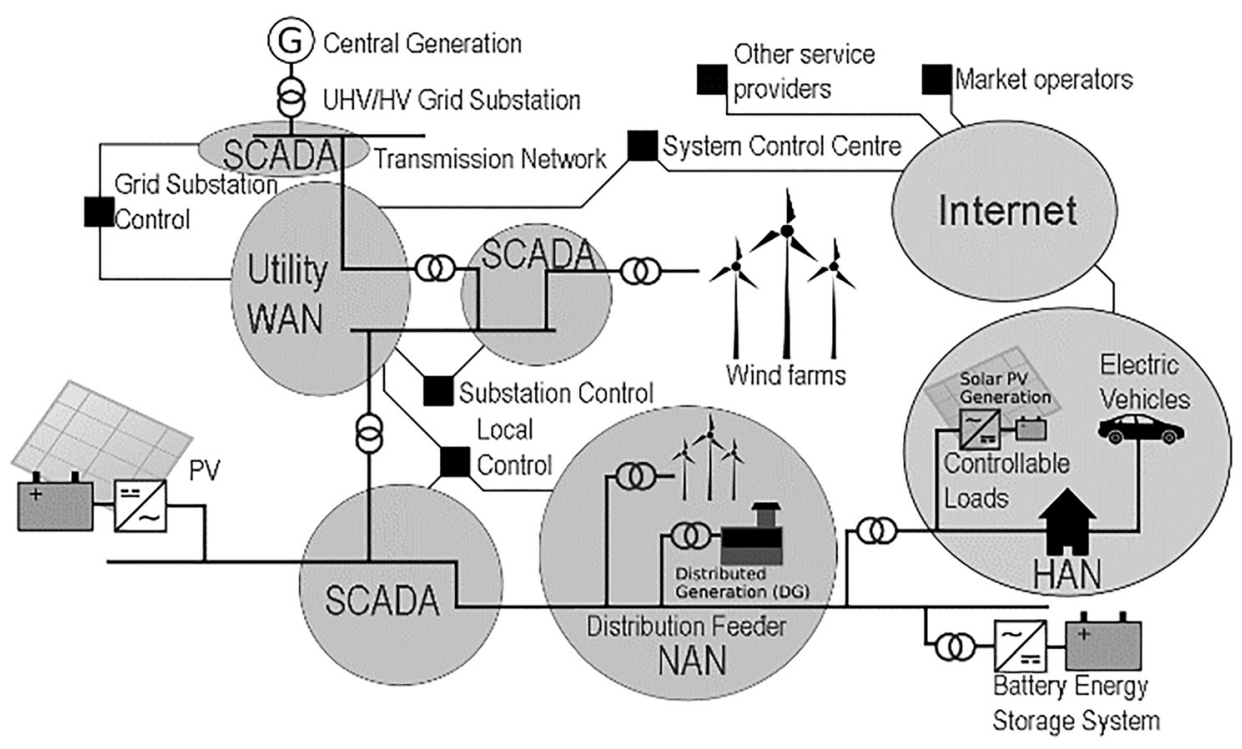

Fig. 1. An example of a smart grid with distributed generation and distributed control (on the basis of [8]) 
heating system more effective and increasing the personal comfort level, in parallel.

The building mass can be used for Demand Side Management (DSM) by its coupling with buildings' air conditioning system, where it can provide a capacity stress reservoir on the demand side with minimal changes to conventional operation and without disturbing thermal comfort in a sacrificial side [13].

It is also accepted, that a DSM is the most important issue for the smart grid balancing, e.g., to utilize the energy produced at the same place and time, to lower the dependence from the distribution grid control. Office and education buildings are said to be ideal for DSM purposes, because of shorter utilization period. It is an interesting conclusion that thermal energy storage can result higher energy demand, but lower costs by shifting away demand from peak hours to lower prices period [14].

DSM can also be practically combined with passive building ventilation for cooling purposes as it was investigated by the authors [15].

Researchers have compared the dynamic behavior of different heat emission systems and highlighted their large influence on thermal comfort: Not only the availability of the thermal mass, but also the interaction between the heating system and the thermal mass has significant importance [16]. This statement is considerable in cooling interaction, too. Direct cooling of the building structure is more acceptable from one side, but that needs special planning and financial investment.

The level of insulation has an important influence on the heat reservoir, at advanced insulation the time constant can be high enough and the stored energy can last for more than $8 \mathrm{~h}$ in a residential building [17] and even more in a building with higher thermal capacitance.

\subsection{Thermal storage connected to electrical micro-grid}

In spite of low conversion efficiency from thermal energy to electrical grid there are some applications, which can work in building environment. A thermoelectric solution can make it possible to use thermal storage in a smart grid bidirectionally, in this new approach the cooling and the warming sides of thermoelectric module are realized by the two sides of a building wall (inside-outside) [18]. Other method for the conversion can be a Stirling engine operating as a generator or a water pump [19].

The less complicated application is one directional demand control. In a smart grid there are programmable consumers and non- or partially programmable consumers. The most referred programmable DSM load is washing machine since its operation can be delayed or scheduled to a period where renewable energy production in the grid is over demand. A thermal storage also can be a programmable load. The buildings' thermal storage can be activated by the Heating, Ventilation and Air Conditioning (HVAC) system or heat pump in cooling mode if present. Smart grid control strategies allow reduction of energy procurement costs by up to $15 \%$ and the consumer's cost by $13 \%$ [20].
Also thermal energy grid can be used for wide-spreading the cooling energy produced in overproduction period. These thermal energy grids are called 4th generation one since they can be used for cooling in district, [21]. Unlike the first three generations' solutions, the development of $4^{\text {th }}$ generation district heating system involves the challenge of more energy efficient buildings as well as being part of an integrated operation of smart energy systems, i.e., integrated smart electricity, gas and thermal grids. The economic advantages of a thermal grid can be based on its energy analysis as it is described by Rezaie and Rosen [22].

This all means above that a thermal storage is absolutely suitable for peak shifting, resulting cost reduction and increasing efficiency of Photo Voltaic (PV) systems [23]. In special cases the legal regulations of a given country are inspiring the stakeholders to realize a smart micro-grid even if the electricity grid is not 'smart' in that relevant area but the Building Management System (BMS) can partly overtake its role.

In this paper an existing governmental higher-educational building is investigated from DSM purposes. The building itself has been renovated in 2002, insulation applied, windows changed that time. On the top of the building, a $22 \mathrm{kWp}$ PV system is installed and has been producing electricity since 2015 .

\section{DYNAMIC CONTROL SOLUTIONS FOR BUILDING MANAGEMENT SYSTEM}

Finding solutions for DSM needs a better understanding of the thermodynamic behavior of the building and the existing BMS. The BMS in this case is a simple central HVAC control, which has been modified by a device, which sends fake temperature data from the tested room. The thermodynamic properties and the control method are described in the followings.

\subsection{Heat capacity and heat resistance}

A building, which has been built by traditional technologies from concrete, should have big heat capacitance. To utilize this well, the structure has to be heat-insulated as much as possible and other energy saving technologies has to be used (at least triple layer glazing, high air tightness, heat recovery ventilating system, etc.). This heat capacitance can be used for store energy inside the structure of the building, with keeping the user habits and comfort in focus. Therefore, it needs a smart or well programmed BMS, which takes the building's heat capacity and the heat losses into consideration for the control of the temperature.

There are several techniques to determine the total resistance $\left(R_{T}\right)$ and capacitance $(C)$ of a building. For new houses it is mandatory in Hungary to issue an Energy Certificate [24], according to decree 7/2006 TNM, which is based on MSZ EN ISO 6946. This certificate contains the conductive loss (or gain) [W/K] for the building, as in line $\Sigma A U+\Sigma l \Psi$ it is described, where $A$ is the envelope area 
$\left[\mathrm{m}^{2}\right] ; U$ is the heat transfer coefficient $\left[\mathrm{W} \mathrm{m}^{-2} \mathrm{~K}^{-1}\right]$; the $l$ is conduction length $[\mathrm{m}]$ and $\Psi$ is thermal conductivity [W $\left.\mathrm{m}^{-1} \mathrm{~K}^{-1}\right]$. The heat capacity for the structure is not calculated in this section of the simplified method, but the specific heat and density values for all construction materials are given, thus solid volume and mass can be calculated easily. The air volume is also given in the certificate. The method could even contain energy analyses, also [25].

Other simulation technique is to build up a thermal resistance model (Fig. 2), to calculate the total resistance, and finally to summarize it [26].

The main building of the Faculty of Engineering and Information Technology, University of Pecs (Fig. 3) was chosen to calculate how much amount of energy can be stored in this building beside good optimization of energy use. A simplified thermal resistance model based in Fig. 2 was drawn and the heat storage capacity of the building was calculated. The total thermal resistance of the building is $R_{T}$ $=0.039 \mathrm{~K} / \mathrm{W}$ and the capacitance is $C=1,140 \mathrm{kWh} / \mathrm{K}$, was rough-calculated according to Table 1.

The calculated thermal capacity is the same amount to $1,000 \mathrm{~m}^{3}$ water tank, which could be considered as investment benchmark of building envelope.

Using the building as cooling storage at $2 \mathrm{~K}$ range of temperature change in the structure is doubling the capacity, which has low influence in the thermal comfort. For better understanding of the thermal behavior, a LabView simulation has been completed. It shows that the time constant of the building is high enough; even 2 days can be considered
(Fig. 4). As boundary condition $22{ }^{\circ} \mathrm{C}$ outside temperature was given, with an estimated $2{ }^{\circ} \mathrm{C}$ cooling success.

Presenting heat properties of the building, better models can be applied than this simple RC circuit model, but this can simply be implemented in control systems. In this specific case a legal regulation made it necessary to start investigation if any surplus energy could be produced by the installed PV system.

The Hungarian Law about the electric energy [27] states, if a facility having its own electric transformer system (from middle to low voltage), they have to make the authorization of the planned PV system as it was a MW size power plant, which would practically around 20 times higher planning and licensing costs.

The solution in this case could have been an isolated system installation, which still can feed into the grid, but a smart control solution switches the PV system off the grid when positive balance occurs (at peak production). That would mean significant loss of potential green energy. A HVAC system is applied for better utilization of potential renewable energy.

Positive balance in energy production and demand can occur on weekends, only and especially in summertime when the building is not occupied (Fig. 5).

A photovoltaic systems' telemetry data monitor connected to the grid-feeding inverters. LabView-based environmental monitoring system is connected by RS485 line to USS protocol. The monitoring system gives the switching sign when grid connected system must be turned into isolated

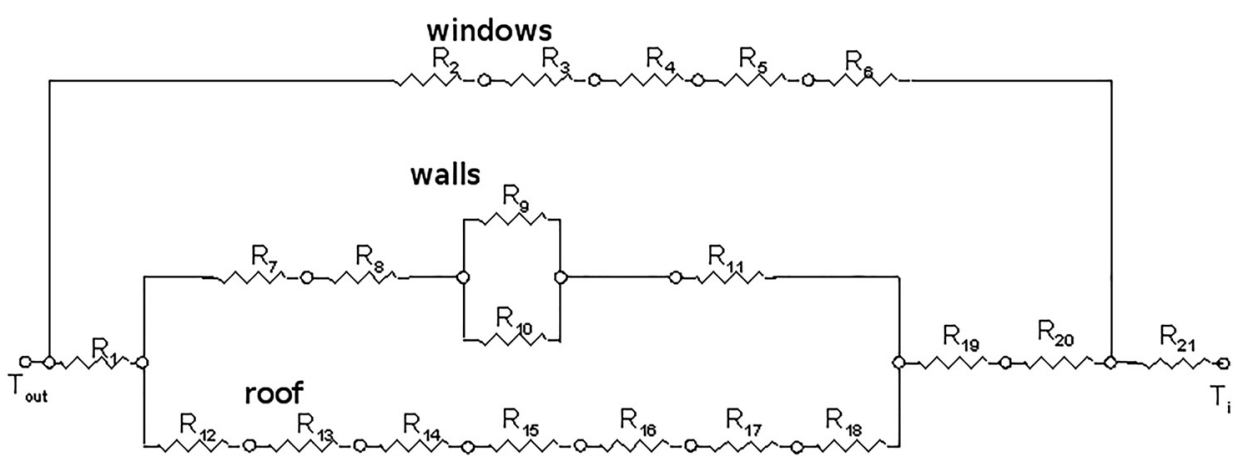

Fig. 2. An example for thermal resistance model of a building

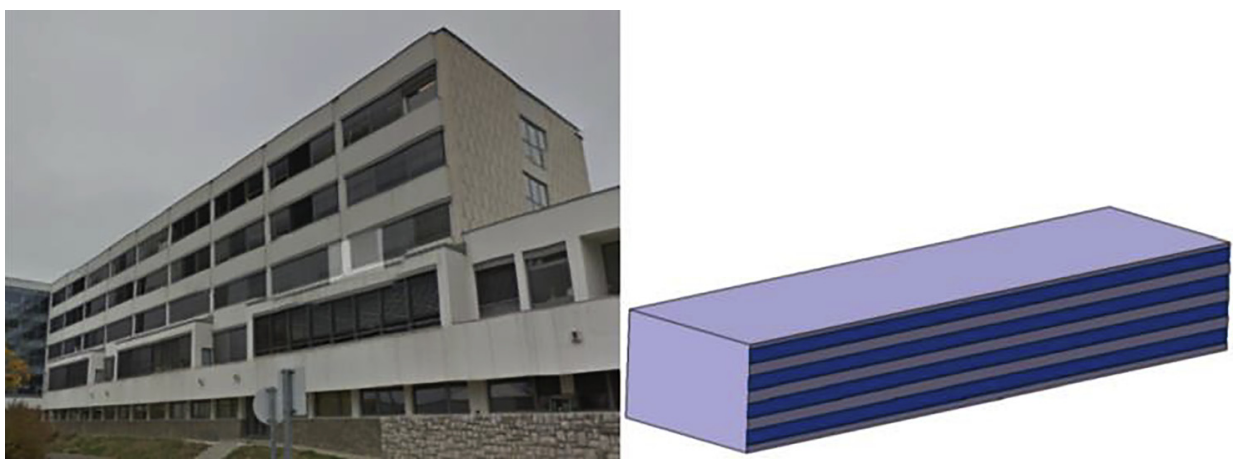

Fig. 3. A photo and the simplified model of the building 
Table 1. Physical parameters of the building envelope

\begin{tabular}{lcccc}
\hline & $\begin{array}{c}\text { Density } \\
\left(\mathrm{kg} \cdot \mathrm{m}^{-3}\right)\end{array}$ & $\begin{array}{c}\text { Specific heat } \\
\left(\mathrm{J} \cdot \mathrm{kg}^{-1} \cdot \mathrm{K}^{-1}\right)\end{array}$ & $\begin{array}{c}\text { Thermal conductivity } \\
\left(\mathrm{W} \cdot \mathrm{m}^{-1} \cdot \mathrm{K}^{-1}\right)\end{array}$ & $\begin{array}{c}\text { Volume in the } \\
\text { building }\left(\mathrm{m}^{3}\right)\end{array}$ \\
\hline Concrete & 2,200 & 880 & 1.2 & 2,121 \\
Thermal isolation & 100 & 1,300 & 0.04 & 540 \\
Air & 1.12 & 1,020 & 0.02 & 27,092 \\
\hline
\end{tabular}

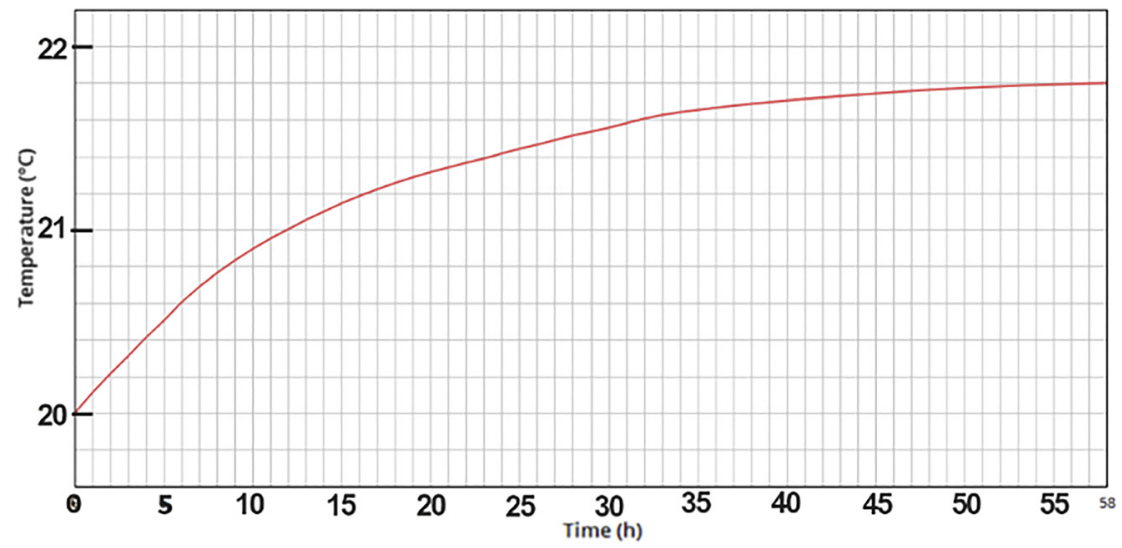

Fig. 4. The simulated temperature change diagram (time in hours, temp. in ${ }^{\circ} \mathrm{C}$ )

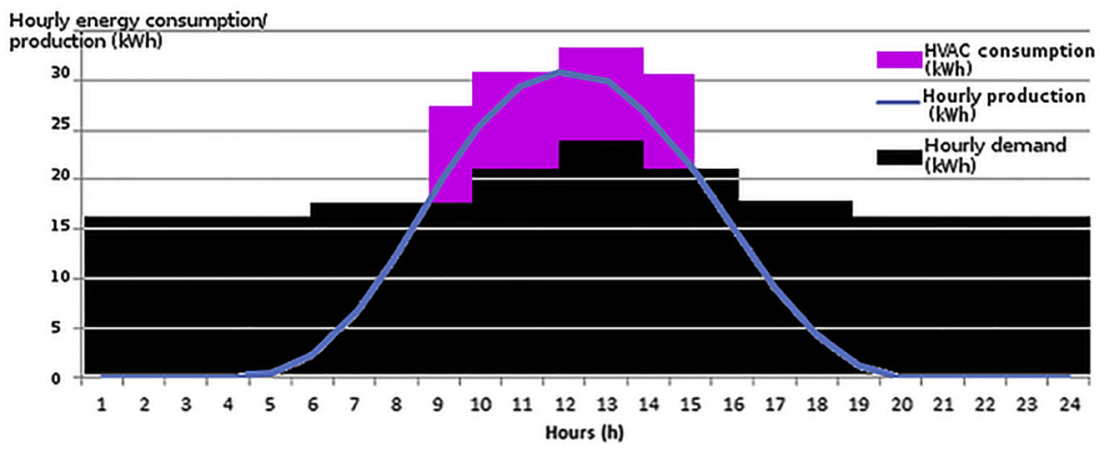

Fig. 5. Production and consumption of the building on a typical weekend day, in middle of June

system when grid feeding is higher than a pre-defined threshold value (currently the value is zero).

At this special case, student hostel building is hosting the $0.4 \mathrm{kV}$ transformer, where 3 pcs of current switches were installed. A current direction sensor was placed (PQRM 510031 type, manufactured by DATCON) at the transformer which senses the current flow and then it switches the operation mode.

\subsection{Building management system}

In normal operation when the energy balance turns into grid feeding, the transmitter sends a sign through its HighVoltage (HV) isolated contact. This operates an Internet Protocol (IP) relay, and sends the sign into the structured IP network with high reliability. On the opposite side, the same hardware converts the sign back to a discrete sign and disconnects the AC side of the inverter from the grid, so the PV production stops immediately. When the protection sign is canceled, the inverter follows the normal protocol and after few minutes it turns back the system into production mode.

As it can be seen in Fig. 5, the surplus energy marked with brighter column can be utilized the way consumers generate heat or cooling energy to store in thermal storage of the building for later use.

A scheme of energy consumption timetable would be necessary to set up, which guarantees the PV system's normal operation. When surplus energy is generated, the BMS involves switchable loads into the system, which are easily controllable (HVAC, heating, domestic hot water production, etc.) and this stored amount of energy types can be used up by residential later.

The solution uses inverters' open channel USS protocol. When the energy production is approaching the energy use, the controller can decide whether to switch the system off the grid, or to use the surplus energy for cooling. 
The aim was to develop a control and monitoring module. With the help of the described hardware the investigation of the consumption habits is feasible; the control of extra loads is manageable. The overall system efficiency can be optimized, connecting the system to BMS system.

\section{CONCLUSION}

In the described application success of integrating the PV system in the BMS means that the surplus energy will not be lost. This case the building uses energy for cooling and the amount of cooling will active until it is needed. It is also clarified, that control strategy increases the consumption, but the overall system reaches higher efficiency at the end. Due to the relatively small sized PV system, the positive balance occurs only few days a year and uses $5-15 \%$ of the heat capacity of the building in ratio.

Increasing the peak power of the PV production it would be necessary to reach $1-2{ }^{\circ} \mathrm{C}$ in cooling range, therefore the comfort values could be analyzed, besides other important parameters and processes. According to the heat resistance model based simulation, the building has a time-constant of 3.5 days by one degrees Kelvin. The useful part of it is 2 days, since the function is exponentially changing.

This kind of thermodynamic control could be a basic feature or the first step for smart buildings. The only thing we need here to integrate the thermodynamic resistance $(R)$ and capacity $(C)$ based function into the control system or the simpler thermostat control. The $R$ and $C$ values can be extracted from the building's energy certificate, which is required in Europe for new buildings and at change of ownership or occupier. The prediction of demand and production is mandatory to maximize the savings; therefore the Authors' previous work [28] in analytic prediction can be also connected, as well as methods based on Artificial Intelligence (AI).

\section{ACKNOWLEDGEMENTS}

István Háber has got $\mathrm{PhD}$ in renewable energy engineering; he is active in smart city topics, smart building researches. Istvan Szabo has got $\mathrm{PhD}$ in renewable energy generation system optimization. Gergely Bencsik was researcher at Energy Consulting Ltd and Basma Naili are $\mathrm{PhD}$ students and supported the work with programming the BMS system and helped in construction.

\section{REFERENCES}

[1] Energy independence and security act of 2007. Public Low 110-140, Dec. 19, 2007 110th US Congress, 2007.

[2] DOE Global Energy Storage Database. Sandia National Renewable Laboratories, [Online]. Available: www.energystorageexchange. org. Accessed: Oct. 9, 2018.
[3] S. Schoenung, "Energy storage system costs update", Sandia National Energy Laboratories, Report, vol. 2730, pp. 1-30, 2011.

[4] J. Thakur and B. Chakraborty, "Smart net metering models for smart grids in India", in International Conference on Renewable Energy Research and Applications, Palermo, Italy, Nov. 22-25, 2015, 2015, pp. 173-177.

[5] S. Sabihuddin, A. Kiprakis, and M. Mueller, "A numerical and graphical review of energy storage technologies”, Energies, vol. 8, no. 1, pp. 172-216, 2015.

[6] H. Zsiborács, et al., "Electricity market challenges of photovoltaic and energy storage technologies in the European Union: Regulatory challenges and responses", Appl. Sci., vol. 10, no. 4, pp. 1472-1498, 2020.

[7] W. Doorsamy and W. A. Cronje, "State estimation on stand-alone DC microgrids through distributed intelligence", in International Conference on Renewable Energy Research and Applications, Palermo, Italy, Nov. 22-25, 2015, 2015, pp. 227-231.

[8] J. B. Ekanayake, N. Jenkins, K. Liyanage, J. Wu, and A. Yokoyama, Smart Grid Technology and Applications. Wiley, 2012.

[9] R. Atia and M. Yamada, "Distributed renewable generation and storage systems sizing in deregulated energy markets", in International Conference on Renewable Energy Research and Applications, Palermo, Italy, Nov. 22-25, 2015, 2015, pp. 258-262.

[10] K. A. Alfaitori, A. Khalil, and A. Asheibi, "Distributed control of photovoltaic-based microgrid", in 4th International Conference on Renewable Energy Research and Applications, Palermo, Italy, Nov. 22-25, 2015, 2015, pp. 203-208.

[11] Y. Utsugi, S. Obara, Y. Ito, and M. Okada, "Planning of the optimal distribution of renewable energy in Hokkaido, Japan", in International Conference on Renewable Energy Research and Applications, Palermo, Italy, Nov. 22-25, 2015, 2015, pp. 254-257.

[12] T. Sakagami, A. Werth, M. Tokoro, Y. Asai, D. Kawamoto, and H. Kitano, "Performance of a DC-based microgrid system in Okinawa", in International Conference on Renewable Energy Research and Applications, Palermo, Italy, Nov. 22-25, 2015, 2015, pp. 311-316.

[13] S. N. Palacio, K. J. Kircher, and K. M. Zhang, "On the feasibility of providing power system spinning reserves from thermal storage", Energy and Build., vol. 104, pp. 131-138, 2015.

[14] A. Arteconi, et al., "Thermal energy storage coupled with PV panels for demand side management of industrial building loads", Appl. Energ., vol. 185, part 2, pp. 1984-1993, 2017.

[15] I. Haber, I. Kistelegdi, and I. Farkas, "Investigation of the solarand wind energy usage of a positive energy factory building", Tech. Gaz., vol. 21, no. 6, pp. 1243-1248, 2014.

[16] G. Reynders, T. Nuytten, and D. Saelens, "Potential of structural thermal mass for demand side management in dwellings", Building and Environ., vol. 64, pp. 187-199, 2013.

[17] H. Wolisz, A. Constantin, R. Streblow, and D. Müller, "Performance assessment for heat distribution systems for sensible heat storage in building thermal mass", in Proceedings of Cleantech for Smart Cities \& Buildings, Lausanne, Switzerland, Sep. 6, 2013, vol. 2, 2013, pp. 945-950.

[18] S. Li, K. H. Lam, and K. W. E. Cheng, "The thermoelectric analysis of different heat flux conduction materials for power generation board", Energies, vol. 10, no. 11, pp. 1-14, 2017.

[19] V. S. Slavin, G. C. Bakos, and K. A. Finnikov, "Conversion of thermal energy into electricity via a water pump operating in Stirling engine cycle", Appl. Energ., vol. 86, no. 7-8, pp. 1162-1169, 2009. 
[20] G. Masy, E. Georges, C. Verhelst, V. Lemort, and P. André, "Smart grid energy flexible buildings through the use of heat pumps and building thermal mass as energy storage in the Belgian context", Sci. and Technol. Built Environ., vol. 21, no. 6, pp. 800-811, 2015.

[21] H. Lund, S. Werner, R. Wiltshire, S. Svendsen, J. E. Thorsen, F. Hvelplund, and B. V. Mathiesen, "4th generation district heating (4GDH): Integrating smart thermal grids into future sustainable energy systems", Energy, vol. 68, pp. 1-11, 2014.

[22] B. Rezaie and M. A. Rosen, "District heating and cooling: Review of technology and potential enhancements", Appl. Energ., vol. 93, pp. 2-10, 2012.

[23] F. Rahimi and A. Ipakchi, "Demand response as a market resource under the smart grid paradigm”, IEEE Trans. Smart Grid, vol. 1, no. 1, pp. 82-88, 2010.

[24] G. Kővári and I. Kistelegdi, "Optimized building automation and control for the improvement of energy efficiency and climate comfort of office buildings", Pollack Periodica, vol. 10, no. 1, pp. 71-82, 2015.

[25] V. Bonetti and G. Kokogiannakis, "Dynamic exergy analysis for the thermal storage optimization of the building envelope", Energies, vol. 10, no. 1, pp. 1-19, 2017.

[26] M. B. Wilson, R. Luck, and P. Mago, "A first-order study of reduced energy consumption via increased thermal capacitance with thermal storage management in a micro-building", Energies, vol. 8, no. 10, pp. 12266-12282, 2015.

[27] 2007 year LXXXVI. Hungarian law-E.ON about electric energy. [Online]. Available: https://www.eon.hu/content/dam/eon/eonhungary/documents/hatarozatok-szabalyzatok-aram/2007.\%20évi \%20LXXXVI.\%20 törvény\%20a\%20villamos\%20energiáról.pdf. Accessed: Apr. 22-25, 2020.

[28] I. Háber, I. Kistelegdi, T. Bötkös, and I. Farkas, "Modeling solar irradiation data for photovoltaic energy-yield prediction", Pollack Periodica, vol. 8, no. 3, pp. 27-34, 2013. 